\title{
Trend of prevalence and incidence of systemic lupus erythematosus in South Korea, 2005 to 2015: a nationwide population-based study
}

\author{
Eun Hui Bae ${ }^{1,}$, Sang Yeob Lim ${ }^{2,}$, Kyung-Do Han ${ }^{3}$, Jin-Hyung Jung ${ }^{3}$, Hong Sang Choi ${ }^{1}$, Ha Yeon Kim ${ }^{1}$, \\ Chang Seong Kim ${ }^{1}$, Seong Kwon $\mathrm{Ma}^{1}$, and Soo Wan Kim ${ }^{1}$
}

\begin{abstract}
${ }^{1}$ Department of Internal Medicine, Chonnam National University Medical School, Gwangju; ${ }^{2}$ Department of Internal Medicine, Korea University Ansan Hospital, Ansan; ${ }^{3}$ Department of Medical Statistics, College of Medicine, The Catholic University of Korea, Seoul, Korea
\end{abstract}

Received: August 15, 2018 Revised : October 1, 2018 Accepted: October 8, 2018

\section{Correspondence to}

Soo Wan Kim, M.D.

Department of Internal

Medicine, Chonnam National

University Medical School 42

Jebong-ro, Dong-gu, Gwangju

61469 , Korea

Tel: $+82-62-220-6271$

Fax : +82-62-225-8578

E-mail: skimw@chonnam.ac.kr

*'These authors contributed equally to this work.
Background/Aims: The aim of this study was to evaluate the trend of incidence and prevalence of systemic lupus erythematosus (SLE) in South Korea from 2005 to 2015 .

Methods: From 2005 to 2015, individuals with SLE were identified from the National Health Insurance database, which records information on almost all Koreans. SLE was defined according to the International Classification of Diseases, 10th revision (ICD-10), code M32. The incidence was calculated per 100,000 person-years. The prevalence was calculated per 100,000 people and stratified by year, age group, sex, region, and income.

Results: The annual prevalence of SLE increased slightly from 21.25/100,000 people in 2005 to $35.45 / 100,000$ people in 2015 . In contrast, the annual incidence of SLE decreased slightly from 5.42/100,000 person-years in 2005 to 3.6/100,000 person-years in 2015. The prevalence and incidence of SLE were 10- and 6-fold higher in women than in men, respectively. The peak age of prevalence and incidence was 30 to 39 years in 2005; in 2015, the peak age of prevalence was 30 to 49 years and of incidence was 20 to 49 years. Regional variation was observed in both incidence and prevalence of SLE. Jeju province showed the highest prevalence of SLE (44.54/100,000 person-years), and Gwangju province showed the highest incidence of SLE (6.98/100,000 person-years) in 2015. The income status did not affect the prevalence or incidence of SLE except in patients without income who received medical aid.

Conclusions: The incidence of SLE has declined, but the prevalence has increased in Korea in recent years. Peak age of SLE trend to right shift in Korea.

Keywords: Lupus erythematosus, systemic; Prevalence; Incidence; Database; Korea

\section{INTRODUCTION}

Systemic lupus erythematosus (SLE) is a rare, chronic autoimmune disease that can vary in severity from mild to potentially life-threatening. To improve its management, it is important to know the prevalence of the disease, including the clinical and socioeconomic characteristics of the affected population [1-3]. Both the magnitude and severity of SLE differ markedly with respect to sex, age, race, and region [4]. The prevalence and 
incidence of SLE are 100 to 150/100,000 and > 5/100,000 person-years, respectively [5-9]. A recent review of the epidemiology of SLE in the Asia-Pacific region showed that the prevalence and incidence were in the range of 4.3 to $45 \cdot 3 / 100,000$ and 0.9 to $3.1 / 100,000$ person-years, respectively [10].

The majority of the epidemiologic data on SLE available in the literature is from single-center or cohort studies, but such studies are costly and time-consuming $[11,12]$. In contrast, the use of population-based data is more convenient and precise; one such database is the National Health Insurance (NHI) in Korea, which records extensive data of almost all Koreans. Previous epidemiologic studies on SLE in South Korea have focused on identifying a way to precisely estimate the prevalence and incidence of SLE using population-based surveillance systems $[13,14]$.

The trend of peak age of the prevalence and incidence of SLE, sex, region, and socioeconomic status has not been reported thus far in Korea. Therefore, the present study aimed to determine the prevalence and incidence of SLE in South Korea, including temporal trends and variations in age, sex, region, and income from 2005 to 2015 by using the Korean NHI database.

\section{METHODS}

\section{Study design and database}

We conducted a nationwide cross-sectional study using the Korean NHI database of the Health Insurance Review Agency from 2005 to 2015 . This database includes all claims data provided by the NHI and the Medical Aid programs [15]. The Korean NHI program is a compulsory social insurance scheme that covers approximately $97 \%$ of the Korean population; the remaining 3\% are protected under the Medical Aid program [16]. The database consists of anonymized data that can be used for research purposes and reports the service code (admission or outpatient clinic), year (billing year), age (year old), region (province), sex (male or female), hospital (private clinic, hospital, or university hospital), department (internal medicine, dermatology, etc.), admission (admission or no admission), and billing number included all claimed national insurance data. The NHI database is credible and well-grounded for its use in managing the national statistical resources.

This study was approved by the Institutional Review Board of the National Institute for Bioethics Policy (NHIS-2018-1-109) and the Chonnam National University Hospital (CHUN-EXP-2017-235) in South Korea, and it was conducted according to the principles of the Declaration of Helsinki. Anonymized and de-identified information was used for analyses, and therefore informed consent was not required.

\section{Identification of SLE cases}

The NHI statisticians compiled data on all patients from institutes nationwide, who were treated under the International Classification of Diseases, 1oth revision (ICD-10), code M32 for 13 years from 2002 to June 2015 (washout period was from 2002 to 2004). The South Korea government has enhanced benefit coverage for four major conditions (cancer, cardiovascular disease, cerebrovascular disease, and rare diseases), and SLE is one of the rare diseases. Within this system, the NHI has established a registration program for rare intractable diseases (code V136). Due to enforced privacy laws, detailed personal information could not be retrieved; instead, each patient was allocated an identification number.

\section{Estimation of prevalence and incidence}

For annual prevalence, the year-specific numerator included subjects with prevalent SLE in the specific calendar year, and the denominator included the mid-year population from the Korean National Statistical Office of the year. For annual incidence, the year-specific numerator included subjects with incident SLE in the specific calendar year, and the denominator included the mid-year population from the Korean National Statistical Office of the year. Crude rates, sex- and age-specific rates, standardized rates adjusted for sex and age using the 2015 mid-year population, and their $95 \%$ confidence intervals (CIs) were calculated. Incident cases of SLE were defined as those without SLE in a particular year (e.g., 2005) and the preceding 2 years (e.g., 2003 to 2004) that met the algorithm in that year (e.g., 2005) and the following year (e.g., 2006). Subgroup analyses were performed according to age ( $<40,40$ to 64 , and $>65$ years), sex, region, and income. Income was stratified into 20 categories (from $\mathrm{P} 1$ [lowest] to P2o [highest]) and a medical aid group (with government-aided medical care). 
Table 1. Systemic lupus erythematosus prevalence by year, 2005 to 2015

\begin{tabular}{|c|c|c|c|c|c|c|c|}
\hline Year & $\begin{array}{c}\text { Total } \\
\text { population }\end{array}$ & $\begin{array}{l}\text { No. of } \\
\text { prevalent } \\
\text { cases }\end{array}$ & $\begin{array}{c}\text { Total crude rate, } \\
/ 100,000 \text { person-years } \\
\text { (95\% CI) }\end{array}$ & $\begin{array}{l}\text { Male } \\
\text { cases }\end{array}$ & $\begin{array}{c}\text { Male crude rate, } \\
\text { /100,000 person-years } \\
\text { (95\% CI) }\end{array}$ & $\begin{array}{c}\text { Female } \\
\text { cases }\end{array}$ & $\begin{array}{c}\text { Female crude rate, } \\
\text { /100,000 person-years } \\
(95 \% \mathrm{CI})\end{array}$ \\
\hline 2005 & $48,030,635$ & 10,208 & $21.25(20.84-21.67)$ & 907 & $3.76(3.51-4.00)$ & 9,301 & $38.94(38.15-39.73)$ \\
\hline 2006 & $48,371,311$ & 11,060 & $22.86(22.44-23.29)$ & 1,055 & $4.34(4.08-4.61)$ & 1,0005 & $41.55(40.74-42.36)$ \\
\hline 2007 & $48,603,519$ & 12,003 & $24.70(24.25-25.14)$ & 1,126 & $4.62(4.35-4.88)$ & 10,877 & $44.93(44.09-45.78)$ \\
\hline 2008 & $49,560,378$ & 12,981 & $26.19(25.74-26.64)$ & 1,202 & $4.83(4.56-5.11)$ & 11,779 & $47.69(46.83-48.55)$ \\
\hline 2009 & $49,884,458$ & 13,914 & $27.89(27.43-28.36)$ & 1,272 & $5.08(4.81-5.36)$ & 12,642 & $50.84(49.95-51.72)$ \\
\hline 2010 & $50,166,793$ & 13,270 & $26.45(26.00-26.90)$ & 1,151 & $4.58(4.31-4.84)$ & 12,119 & $48.45(47.58-49.31)$ \\
\hline 2011 & $50,445,164$ & 14,216 & $28.18(27.72-28.64)$ & 1,270 & $5.02(4.75-5.30)$ & 12,946 & $51.45(50.56-52.34)$ \\
\hline 2012 & $50,763,154$ & 15,130 & $29.81(29.33-30.28)$ & 1,377 & $5.41(5.13-5.70)$ & 13,753 & $54.3(53.39-55.21)$ \\
\hline 2013 & $51,013,675$ & 16,152 & $31.66(31.17-32.15)$ & 1,517 & $5.94(5.64-6.24)$ & 14,635 & $57.45(56.52-58.38)$ \\
\hline 2014 & $51,281,917$ & 17,324 & $33.78(33.28-34.28)$ & 1,621 & $6.32(6.01-6.62)$ & 15,703 & $61.30(60.35-62.26)$ \\
\hline 2015 & $51,574,044$ & 18,282 & $35.45(34.93-35.96)$ & 1,771 & $6.86(6.54-7.18)$ & 16,511 & $64.09(63.12-65.07)$ \\
\hline
\end{tabular}

CI, confidence interval.

\section{Statistical analyses}

Continuous variables are presented as mean and standard deviation, and categorical variables are presented as number and percentage. To compare the characteristics between the cohorts, the Student's $t$ test was used for continuous variables and the chi-square test was used for binary and categorical variables. All statistical tests were two-tailed, and the significance level was set at $p<$ 0.05. All statistical analyses were performed using SAS version 9.3 (SAS Institute, Cary, NC, USA) software program.

\section{RESULTS}

\section{Prevalence}

From 2005 to 2015, the average number of prevalent cases of SLE was 14,049 (crude rate, 28.02; 95\% CI, 20.84 to 32.15), of which 12,752 (90.8\%; crude rate, 51; $95 \%$ CI, 38.15 to 58.38 ) were women (Table 1 ).

\section{Trend in prevalence by year}

There was a linear increasing annual trend in the prevalence of SLE, from 21.25/100,000 person-years in 2005 to 35.45/100,000 person-years in 2015 (Table 1, Fig. 1A). After adjusting for length of follow-up, age, and sex, there was still an increasing linear trend in the prevalence, from
$20.99 / 100,000$ person-years in 2005 to $35.45 / 100$, o0o person-years in 2015 .

\section{Sex and age}

Every year, women showed a significantly higher prevalence of SLE than men. In addition, from 2005 to 2015 , an increasing trend was observed in both sexes, which was more marked in women (Fig. 1A). The overall peak age of prevalence was 30 to 39 years in 2005, but the peak age was higher ( 40 to 49 years) in 2015. From 2005 to 2015 , the peak age of SLE prevalence among men was not different in all ages $>20$ years. However, the peak age of prevalence among women was similar to the overall prevalence graph ( 30 to 39 years of age in 2005 and 30 to 49 years of age in 2015) (Fig. 2A).

\section{Region}

In 2005, Jeju province had the highest prevalence of SLE (25.09/100,000 person-years), and Jeonnam province had the lowest prevalence of SLE (13.73/100,000 person-years). In 2015, Gyeongnam province had the lowest prevalence of SLE (27.32/100,000 person-years), and Jeju province had the highest prevalence of SLE (44.54/100,000 person-years) (Fig. 3A).

Income

In 2015, the prevalence of SLE was not significantly dif- 
Trend of SLE prevalence, 2005-2015

$$
\rightarrow \text { Total } \rightarrow \text { Male } \rightarrow \text { Female }
$$

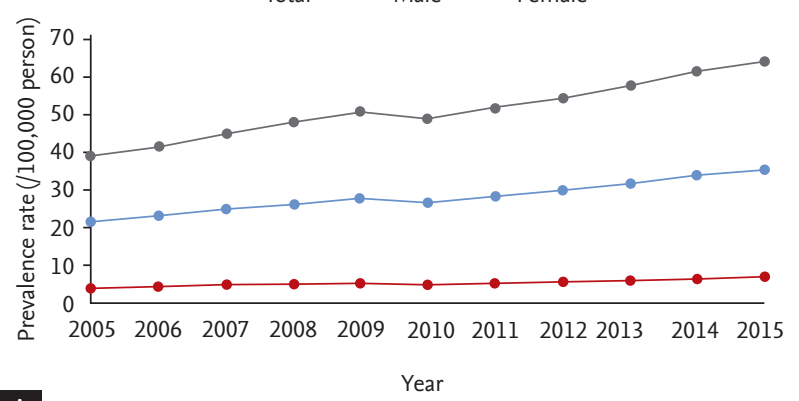

a

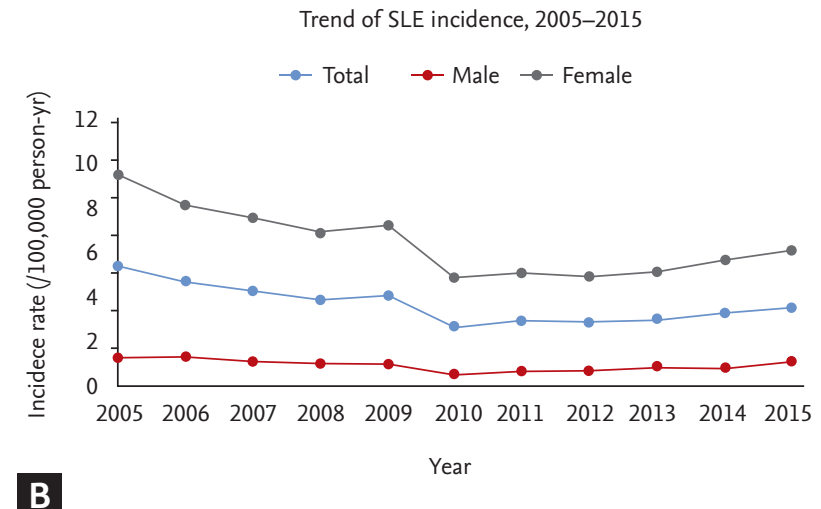

B

Figure 1. (A) Trend of systemic lupus erythematosus (SLE) prevalence from 2005 to 2015 and (B) trend of SLE incidence from 2005 to 2015 .

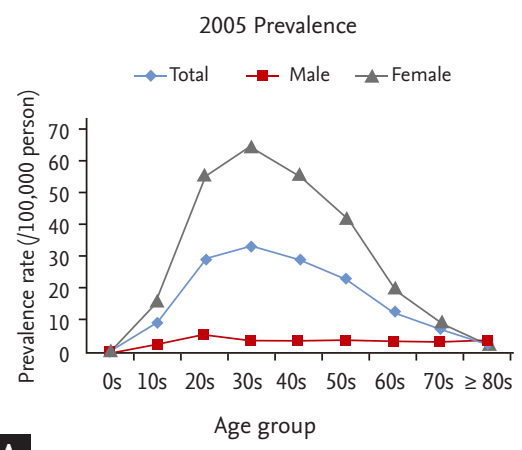

A

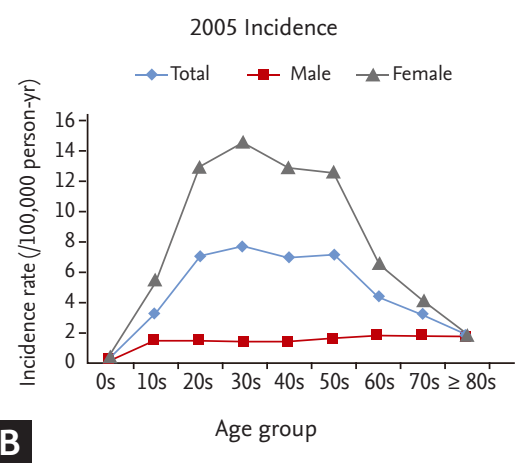

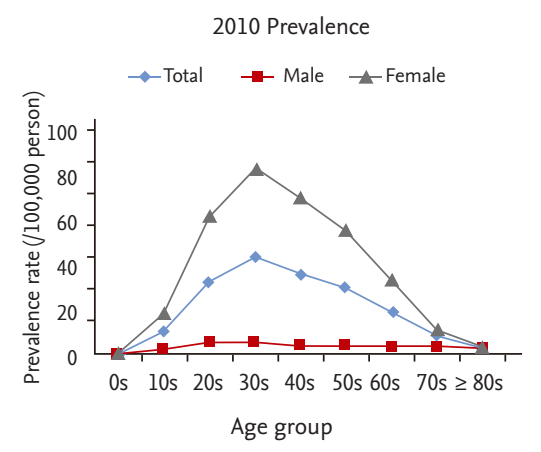

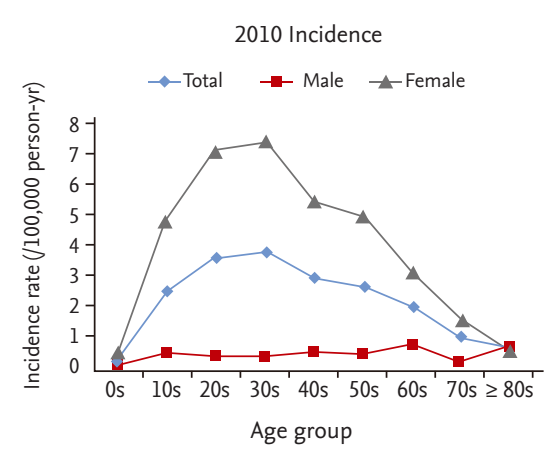

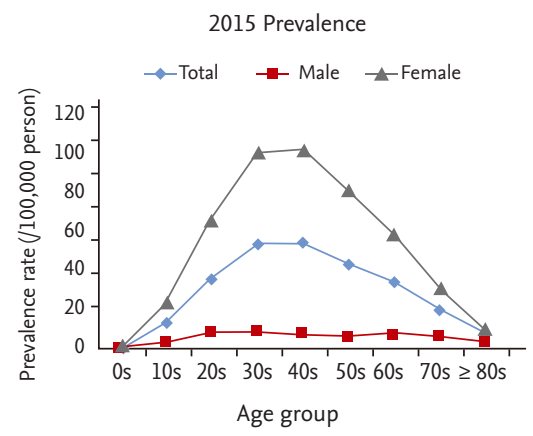

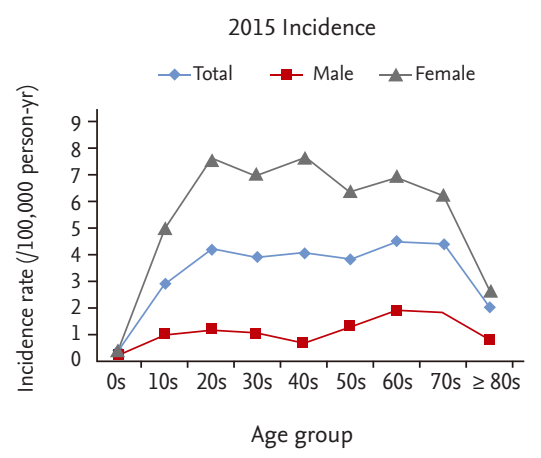

Figure 2. Peak age of (A) prevalence and (B) incidence in 2005, 2010, and 2015.

ferent among all income groups, but the medical aid group showed higher prevalence and incidence than all other income groups (Fig. 4).

\section{Incidence}

From 2005 to 2015 , the number of incident cases of SLE was 1,849 patients (crude rate, 3.72; 95\% CI, 2.55 to 5.63) of which 1,617 (87.58\%) (crude rate, 6.52; 95\% CI, 4.62 to 10.01) were women (Table 2).

Trend in incidence by year

Fig. $1 \mathrm{~B}$ shows the trend in incidence by year. There was an annual decrease in the incidence of SLE from 2005 to 2010, with a peak incidence in $2005(5.42 / 100,000$ 

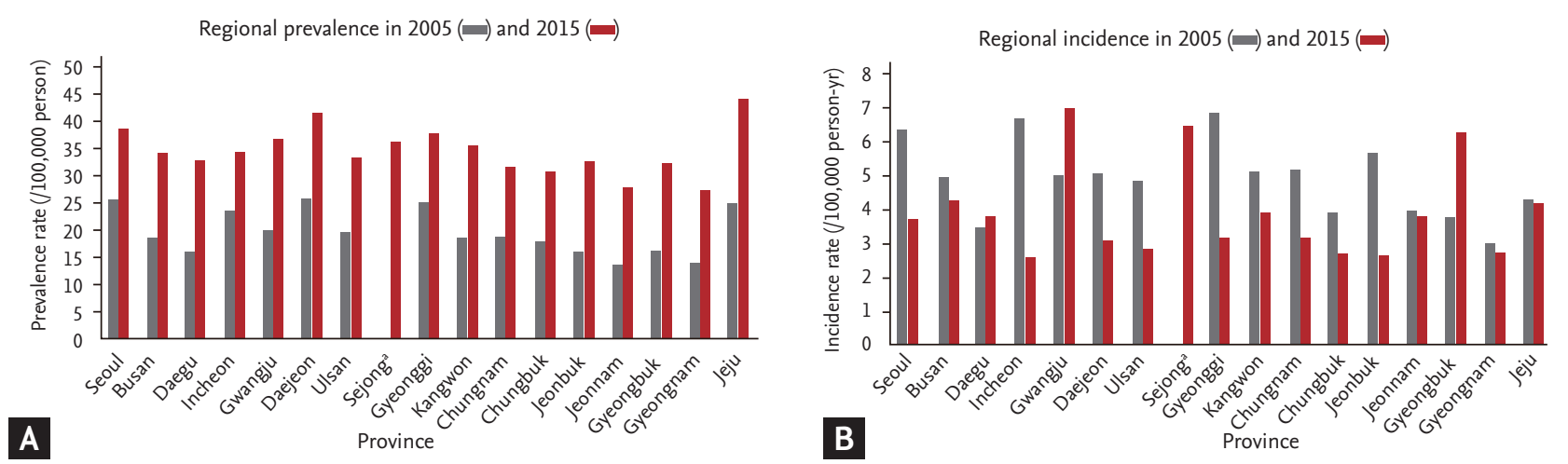

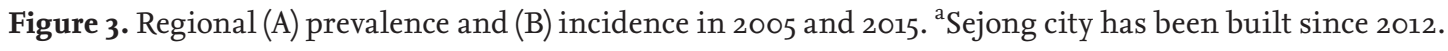
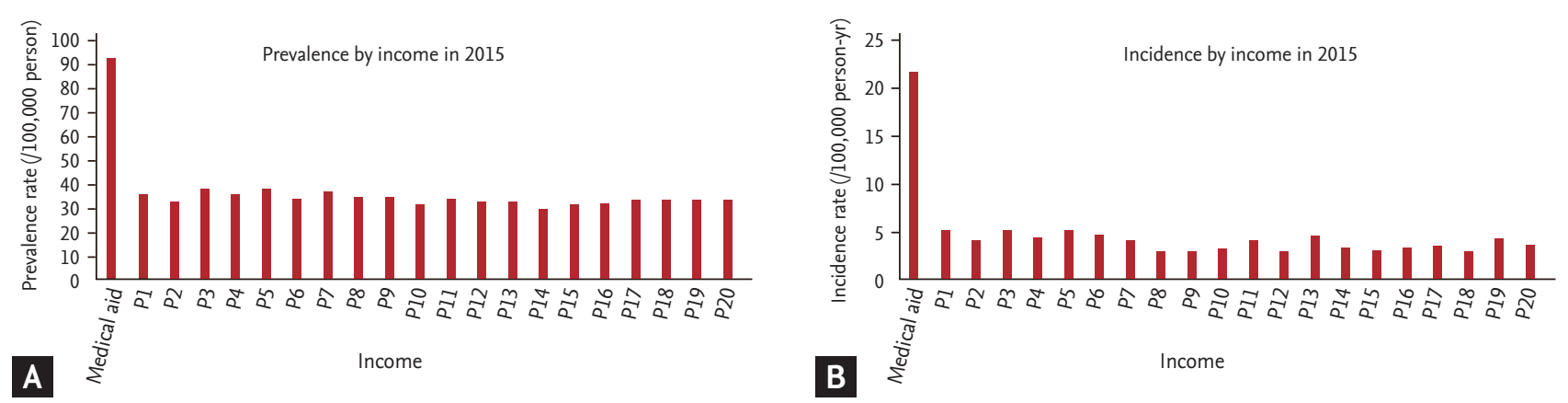

Figure 4. (A) Prevalence and (B) incidence rate by income in 2005.

Table 2. Systemic lupus erythematosus incidence by year, 2005 to 2015

\begin{tabular}{|c|c|c|c|c|c|c|c|}
\hline Year & $\begin{array}{c}\text { Total } \\
\text { population }\end{array}$ & $\begin{array}{l}\text { No. of } \\
\text { incident } \\
\text { cases }\end{array}$ & $\begin{array}{l}\text { Total crude rate, } \\
\text { /100,000 person- } \\
\text { years }(95 \% \mathrm{CI})\end{array}$ & $\begin{array}{l}\text { Male } \\
\text { cases }\end{array}$ & $\begin{array}{l}\text { Male crude rate, } \\
\text { /100,000 person- } \\
\text { years }(95 \% \mathrm{CI})\end{array}$ & $\begin{array}{c}\text { Female } \\
\text { cases }\end{array}$ & $\begin{array}{c}\text { Female crude rate, } \\
\text { /100,000 person- } \\
\text { years }(95 \% \mathrm{CI})\end{array}$ \\
\hline 2005 & $48,020,871$ & 2,602 & $5.42(5.21-5.63)$ & 306 & $1.27(1.13-1.41)$ & 2,296 & $9.62(9.22-10.01)$ \\
\hline 2006 & $48,359,044$ & 2,298 & $4.75(4.56-4.95)$ & 317 & $1.31(1.16-1.45)$ & 1,981 & $8.23(7.87-8.59)$ \\
\hline 2007 & $48,588,945$ & 2,106 & $4.33(4.15-4.52)$ & 265 & $1.09(0.96-1.22)$ & 1,841 & $7.61(7.26-7.96)$ \\
\hline 2008 & $49,543,570$ & 1,967 & $3.97(3.79-4.15)$ & 248 & $1.00(0.87-1.12)$ & 1,917 & $6.96(6.63-7.29)$ \\
\hline 2009 & $49,865,845$ & 2,046 & $4.10(3.93-4.28)$ & 229 & $0.92(0.80-1.03)$ & 1,817 & $7.31(6.98-7.65)$ \\
\hline 2010 & $50,146,319$ & 1,350 & $2.69\left(2.55^{-2.84}\right)$ & 127 & $0.50(0.42-0.59)$ & 1,223 & $4.89(4.62-5.17)$ \\
\hline 2011 & $50,423,558$ & 1,460 & $2.90(2.75-3.04)$ & 172 & $0.68(0.58-0.78)$ & 1,288 & $5.12(4.84-5.40)$ \\
\hline 2012 & $50,740,294$ & 1,434 & $2.83(2.68-2.97)$ & 175 & $0.69(0.59-0.79)$ & 1,259 & $4.97(4.70-5.25)$ \\
\hline 2013 & $50,989,598$ & 1,545 & $3.03(2.88-3.18)$ & 225 & $0.88(0.77-1.00)$ & 1,320 & $5.19(4.91-5.47)$ \\
\hline 2014 & $51,256,546$ & 1,678 & $3.27(3.12-3.43)$ & 212 & $0.83(0.71-0.94)$ & 1,466 & $5.73(5.44-6.02)$ \\
\hline 2015 & $51,547,020$ & 1,854 & $3.60(3.43-3.76)$ & 276 & $1.07(0.94-1.20)$ & 1,578 & $6.13(5.83-6.43)$ \\
\hline
\end{tabular}

CI, confidence interval. 
Table 3. Death rate of systemic lupus erythematosus patients during follow-up

\begin{tabular}{|c|c|c|c|c|c|c|c|c|c|}
\hline \multirow{2}{*}{ Age group $^{\mathrm{a}}$} & \multicolumn{3}{|c|}{ Total } & \multicolumn{3}{|c|}{ Male } & \multicolumn{3}{|c|}{ Female } \\
\hline & Number & Death & Death rate & Number & Death & Death rate $^{\mathrm{a}}$ & Number & Death & Death rate \\
\hline$<10$ & 200 & 7 & 5.60 & 67 & 1 & 2.23 & 133 & 6 & $7 \cdot 49$ \\
\hline $10 \mathrm{~s}$ & 2,102 & 59 & 5.02 & 353 & 10 & 4.81 & 1,749 & 49 & 5.06 \\
\hline $20 \mathrm{~s}$ & 3,839 & 118 & 5.00 & 441 & 8 & 3.00 & 3,398 & 110 & 5.25 \\
\hline $30 \mathrm{~s}$ & 4,756 & 148 & 5.01 & 457 & 24 & 8.82 & 4,299 & 124 & 4.63 \\
\hline $40 \mathrm{~s}$ & 4,181 & 194 & 7.82 & 422 & 35 & $14 \cdot 36$ & 3,759 & 159 & 7.10 \\
\hline $50 \mathrm{~s}$ & 2,937 & 211 & 13.33 & 345 & 43 & 25.61 & 2,592 & 168 & 11.87 \\
\hline $60 \mathrm{~s}$ & 1,493 & 252 & $35 \cdot 48$ & 290 & 80 & 66.50 & 1,203 & 172 & 29.16 \\
\hline $70 \mathrm{~s}$ & 716 & 211 & 87.55 & 148 & 66 & 150.94 & 568 & 145 & $73 \cdot 50$ \\
\hline$\geq 80$ & 116 & 61 & $225 \cdot 31$ & 29 & 19 & 274.01 & 87 & 42 & 208.54 \\
\hline Total & 20,340 & 1,261 & 10.82 & $2,55^{2}$ & 286 & 20.81 & 17,788 & 975 & 9.48 \\
\hline
\end{tabular}

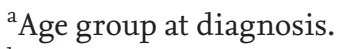

${ }^{\mathrm{b}}$ Per 1,000 person.

person-years). The lowest incidence was noted in 2010 (2.69/100,000 person-years); thereafter, the incidence increased slightly every year until 2015 (3.6/100,000 person-years). After adjusting for the length of follow-up, age, and sex, the trend was still similar (5.47/100,000 person-years in 2005, 2.69/100,000 person-years in 2010, and 3.59/100,000 person-years in 2015).

\section{Sex and age}

From 2005 to 2015, the incidence of SLE among women was 6- to 8-fold higher than that among men. In addition, women were significantly younger than men at diagnosis. At all ages, the incidence of SLE was higher among women than among men. The peak age of incidence for women ( 30 to 39 years) was lower than that for men (6o to 79 years) in 2005 . However, in 2015, there were two peak ages of incidence ( 20 to 29 years and 40 to 49 years). The peak age of incidence for men was similar in the entire age group over 20 years in 2005 , but there was a peak age in 2015 (60 to 79 years) (Fig. 2B).

\section{Region}

There was geographic variation in the incidence of SLE from 2005 to 2015. In 2015, the lowest incidence occurred in Inchon province (3.87/100,000 person-years) and the highest incidence occurred in Gwangju province (6.98/100,000 person-years) (Fig. 3B). However, in 2005, Gyeongnam province showed the lowest inci- dence (3.02/100,000 person-years) and Gyeonggi province showed the highest incidence of SLE (6.82/100,000 person-years) (Fig. 3B).

\section{Death rate}

Table 3 shows the death rate of the total, male, and female patients with SLE. Men showed a higher death rate than women, and this difference was prominent in patients over the age of 30 years.

\section{DISCUSSION}

In this study, we determined the nationwide prevalence and incidence of SLE in South Korea by using the NHI claims data that covered almost all Koreans. Our main finding was that the incidence of SLE in South Korea decreased, whereas the prevalence of SLE increased in the last decade.

In our study, the average prevalence of SLE in South Korea was 28.02/100,000 person-years from 2005 to 2015 . Overall, the prevalence of SLE is 30 to 50/100,000 people across Asian countries (except Taiwan [97.5/100,000 person-years]) [17-21] and 20 to 70/100,000 people in Europe [22-29]. The prevalence of SLE in Korea reported in our study was lower than that reported in both China (31.1 to 46.5/100,000 person-years) and Japan (7.0/100,000 men, 68.4/100,000 women) [30]. Similarly, our reported preva- 
lence was lower than that reported in America; the prevalence of SLE is highest in America (100 to 150/100,000 people), including USA [5-9,31,32], Canada [33,34], and Puerto Rico [35], compared to all other countries worldwide [30].

The prevalence of SLE in South Korea and Taiwan was highest in the age group of 30 to 39 years. In contrast, the prevalence of SLE in the UK and Norway was highest in the age groups of 50 to 59 years and 60 to 69 years, respectively $[20,24,36]$. In addition, we confirmed female predominance in the prevalence of SLE, with approximately 10-fold higher prevalence in women than in men. The female-to-male ratio of patients with SLE was similar to that reported previously $(\sim 5: 1$ to $\sim 10: 1)$ $[7,8,21,24,26,29,30,37]$. Studies have reported that this ratio tends to increase with age and peaks during the childbearing ages, declining slowly thereafter $[20,24,29,36]$.

In this study, we observed regional variation in the prevalence of SLE, with the highest prevalence in Jeju province, highest incidence in Gwangju province, lowest prevalence in Gyeongnam province, and lowest incidence in Incheon province. The incidence rate of most provinces decreased, except Gwangju and Gyeongbuk provinces. Consistent with our findings, the UK has reported regional variations in SLE prevalence and incidence [30]. Such geographical variation could reflect differences in the genetic mixture of the population or variation in environmental exposure. For example, countries near the equator are more exposed to ultraviolet radiation than those located further away from the equator, which may be an environmental trigger for SLE [38]. Korea has a relatively small geographical area and a homogenous race. Although regional variation has not been previously noted in Korea, the present study suggests that there is regional variation in even small areas and within a single race. One of possibility of this regional variation may be distribution of SLE specialists or hometowns of the principle investigators of national SLE cohort studies.

The annual prevalence of SLE showed an increasing trend and the peak age of prevalence increased from 2005 to 2015, which suggests improved treatment of SLE and decreased mortality rate. This is a common phenomenon in developed countries, and similar trends were observed in the UK [30]. Since Korea is an aging society, many diseases including SLE show a similar trend (right shift) in the peak age of prevalence.

In this study, the average incidence was 3.72/100,000 person-years from 2005 to 2015 . The incidence of SLE was $>5 / 100,000$ in the USA $[6,8,9,20]$ and 3 to $5 / 100,000$ person-years in Europe [22-26,26] and Asian countries [19-21]. Our result was comparable to the incidence of SLE in Hong Kong and Taiwan. In addition, the SLE incidence in the present study was approximately 6- to 8-fold higher in women than in men, which is similar to the reported difference of 5 - to 8 -fold in previous studies $[19,20,24,26,29,36]$.

Similar to the case in Taiwan [20], the incidence of SLE increased continuously with age until it reached a peak, after which, it declined slowly, as did the prevalence. However, the incidence of SLE among female Norwegians exhibited a bimodal pattern, with the first and second peaks occurring at 16 to 29 years and 50 to 59 years, respectively. This pattern might be related to the use of contraceptive pills during the reproductive age or hormone therapy after menopause [36]. In other European countries, including the UK, Spain, and Denmark, the incidence of SLE increased until the age of 20 to 39 years and remained high thereafter up to the age of 50 to 69 years, although there are some differences in the age at which the incidence peaks $[22,26,27]$. In USA, the incidence of SLE appears to increase steadily with age $[10,11,32]$. In the Caucasian population, late-onset SLE is reported to be more prevalent than early onset SLE [39] and the clinical course is considered to be benign [40]. In contrast, in Asians, SLE is known to be more severe and have a higher mortality rate than in other populations [41]. Our study showed higher death rates in aged persons than in young people and in men than in women. These findings may explain the higher peak age in Korea compared to both Europe and USA and the higher incidence among in the elderly population compared to young people.

We observed an increasing trend in the incidence of SLE during the last decade. Several studies reported a significant increase in the incidence of SLE over several decades [6,29]; however, recent studies conducted over a relatively short period showed almost constant trends in the incidence of SLE $[27,36]$. The increasing trend reported in the present study might be explained by the increase in social awareness of the disease and wide coverage of the copayment beneficiaries program for rare 
diseases. In other words, prevalence can be statistically presumed to be a decrease in the number of deaths after diagnosis (prevalence $=$ incidence $\times$ disease duration). Therefore, we could cautiously assume SLE management as better than in the past.

This study also showed that the income level did not affect the prevalence and incidence of SLE, except in patients without income who received medical aid. Medical aid group showed that the incidence is 4 to 5 times higher than the upper income, and the prevalence is about 2.5 to 3 times higher than the upper income. As a result, it seems that Korea's excellent medical care system supports treatment of SLE better than in the past.

Despite our important findings, this study had a few limitations. First, some apparent limitations of using the NHI database stem from the lack of accurate diagnosis, because the original purpose of the data was to manage the NHI rather than use in academic evaluation. Second, the administrative claims data analyzed in this study were obtained when subjects visited healthcare institutions. Therefore, no information was available for SLE patients who did not visit a healthcare institution, which could underestimate the SLE burden. However, this may not have had a substantial impact on our findings, as the NHI claims data cover almost all Koreans and the wide coverage of the NHI system has made access to health institutions easy for the Korean population. Nevertheless, the strength of this study was that the trend of the prevalence and incidence of all Korean SLE patients was evaluated using national big database.

In summary, this study showed that the incidence of SLE in South Korea decreased in the last decade, whereas the prevalence increased. This finding of increased prevalence of SLE suggests that this disease is no longer rare and will have implications for future healthcare planning. Age, sex, and region were found to be risk factors for SLE. Our data confirmed the known predilection of SLE in women. The peak age of diagnosis is middle age, contrary to the generally held belief that lupus mainly targets young people. Furthermore, there is regional variation in the prevalence and incidence in different regions of Korea, and income is not a risk factor for SLE prevalence and incidence in Korea.

\section{KEY MESSAGE}

1. Incidence of systemic lupus erythematosus (SLE) in South Korea decreased, whereas the prevalence of SLE increased in the last decade.

2. Incidence and prevalence of SLE showed regional variation in even small areas and within a single race (South Korea).

3. The annual prevalence of SLE showed an increasing trend and the peak age of prevalence increased from 2005 to 2015 , which suggests improved treatment of SLE and decreased mortality rate.

\section{Conflict of interest}

No potential conflict of interest relevant to this article was reported.

\section{Acknowledgments}

This research was supported by the Bio \& Medical Technology Development Program of the NRF funded by the Korean government, MSIT (2017M3A9E8023001).

\section{REFERENCES}

1. Gudmundsson S, Steinsson K. Systemic lupus erythematosus in Iceland 1975 through 1984. A nationwide epidemiological study in an unselected population. J Rheumatol 1990;17:1162-1167.

2. Bernatsky S, Joseph L, Pineau CA, Tamblyn R, Feldman DE, Clarke AE. A population-based assessment of systemic lupus erythematosus incidence and prevalence: results and implications of using administrative data for epidemiological studies. Rheumatology (Oxford) 2007;46:18141818 .

3. Bernatsky S, Lix L, Hanly JG, et al. Surveillance of systemic autoimmune rheumatic diseases using administrative data. Rheumatol Int 2011;31:549-554.

4. Bongu A, Chang E, Ramsey-Goldman R. Can morbidity and mortality of SLE be improved? Best Pract Res Clin Rheumatol 2002;16:313-332.

5. Hochberg MC, Perlmutter DL, Medsger TA, et al. Prevalence of self-reported physician-diagnosed systemic lupus erythematosus in the USA. Lupus 1995;4:454-456. 
6. Uramoto KM, Michet CJ Jr, Thumboo J, Sunku J, O'Fallon WM, Gabriel SE. Trends in the incidence and mortality of systemic lupus erythematosus, 1950-1992. Arthritis Rheum 1999;42:46-50.

7. Chakravarty EF, Bush TM, Manzi S, Clarke AE, Ward MM. Prevalence of adult systemic lupus erythematosus in California and Pennsylvania in 2000: estimates obtained using hospitalization data. Arthritis Rheum 2007;56:20922094 .

8. Feldman CH, Hiraki LT, Liu J, et al. Epidemiology and sociodemographics of systemic lupus erythematosus and lupus nephritis among US adults with Medicaid coverage, 2000-2004. Arthritis Rheum 2013;65:753-763.

9. Furst DE, Clarke AE, Fernandes AW, Bancroft T, Greth W, Iorga SR. Incidence and prevalence of adult systemic lupus erythematosus in a large US managed-care population. Lupus 2013;22:99-105.

10. Jakes RW, Bae SC, Louthrenoo W, Mok CC, Navarra SV, Kwon N. Systematic review of the epidemiology of systemic lupus erythematosus in the Asia-Pacific region: prevalence, incidence, clinical features, and mortality. Arthritis Care Res (Hoboken) 2012;64:159-168.

11. Voss A, Green A, Junker P. Systemic lupus erythematosus in Denmark: clinical and epidemiological characterization of a county-based cohort. Scand J Rheumatol 1998;27:98-105.

12. Williams HJ, Alarcon GS, Joks R, et al. Early undifferentiated connective tissue disease (CTD). VI. An inception cohort after 10 years: disease remissions and changes in diagnoses in well established and undifferentiated CTD. J Rheumatol 1999;26:816-825.

13. Ju JH, Yoon SH, Kang KY, et al. Prevalence of systemic lupus erythematosus in South Korea: an administrative database study. J Epidemiol 2014;24:295-303.

14. Shim JS, Sung YK, Joo YB, Lee HS, Bae SC. Prevalence and incidence of systemic lupus erythematosus in South Korea. Rheumatol Int 2014;34:909-917.

15. Song SO, Jung CH, Song YD, et al. Background and data configuration process of a nationwide population-based study using the Korean National Health Insurance System. Diabetes Metab J 2014;38:395-403.

16. Hong JS, Kang HC. Seasonal variation in case fatality rate in Korean patients with acute myocardial infarction using the 1997-2006 Korean National Health Insurance Claims Database. Acta Cardiol 2014;69:513-521.

17. Xiang YJ, Dai SM. Prevalence of rheumatic diseases and disability in China. Rheumatol Int 2009;29:481-490.

18. Zeng QY, Chen R, Darmawan J, et al. Rheumatic diseases in China. Arthritis Res Ther 2008;10:R17.

19. Mok CC, To CH, Ho LY, Yu KL. Incidence and mortality of systemic lupus erythematosus in a southern Chinese population, 2000-2006. J Rheumatol 2008;35:1978-1982.

20. Yeh KW, Yu CH, Chan PC, Horng JT, Huang JL. Burden of systemic lupus erythematosus in Taiwan: a population-based survey. Rheumatol Int 2013;33:1805-1811.

21. Iseki K, Miyasato F, Oura T, Uehara H, Nishime K, Fukiyama K. An epidemiologic analysis of end-stage lupus nephritis. Am J Kidney Dis 1994;23:547-554.

22. Hopkinson ND, Doherty M, Powell RJ. The prevalence and incidence of systemic lupus erythematosus in Nottingham, UK, 1989-1990. Br J Rheumatol 1993;32:110-115.

23. Johnson AE, Gordon C, Palmer RG, Bacon PA. The prevalence and incidence of systemic lupus erythematosus in Birmingham, England. Relationship to ethnicity and country of birth. Arthritis Rheum 1995;38:551-558.

24. Nightingale AL, Farmer RD, de Vries CS. Systemic lupus erythematosus prevalence in the UK: methodological issues when using the General Practice Research Database to estimate frequency of chronic relapsing-remitting disease. Pharmacoepidemiol Drug Saf 2007;16:144-151.

25. Stahl-Hallengren C, Jonsen A, Nived O, Sturfelt G. Incidence studies of systemic lupus erythematosus in Southern Sweden: increasing age, decreasing frequency of renal manifestations and good prognosis. J Rheumatol 2000;27:685-691.

26. Alonso MD, Llorca J, Martinez-Vazquez F, et al. Systemic lupus erythematosus in northwestern Spain: a 20-year epidemiologic study. Medicine (Baltimore) 2011;90:350-358.

27. Laustrup H, Voss A, Green A, Junker P. Occurrence of systemic lupus erythematosus in a Danish community: an 8-year prospective study. Scand J Rheumatol 2009;38:128132.

28. Govoni M, Castellino G, Bosi S, Napoli N, Trotta F. Incidence and prevalence of systemic lupus erythematosus in a district of north Italy. Lupus 2006;15:110-113.

29. Alamanos Y, Voulgari PV, Siozos C, et al. Epidemiology of systemic lupus erythematosus in northwest Greece 19822001. J Rheumatol 2003;30:731-735.

30. Rees F, Doherty M, Grainge M, Davenport G, Lanyon P, Zhang W. The incidence and prevalence of systemic lupus erythematosus in the UK, 1999-2012. Ann Rheum Dis 2016;75:136-141. 
31. Ward MM. Prevalence of physician-diagnosed systemic lupus erythematosus in the United States: results from the third national health and nutrition examination survey. J Womens Health (Larchmt) 2004;13:713-718.

32. Naleway AL, Davis ME, Greenlee RT, Wilson DA, McCarty DJ. Epidemiology of systemic lupus erythematosus in rural Wisconsin. Lupus 2005;14:862-866.

33. Smith CB, Johnson CN, King GM. Assessment of polyaromatic hydrocarbon degradation by potentially pathogenic environmental Vibrio parahaemolyticus isolates from coastal Louisiana, USA. Mar Pollut Bull 2012;64:138-143.

34. Peschken CA, Esdaile JM. Systemic lupus erythematosus in North American Indians: a population based study. J Rheumatol 2000;27:1884-1891.

35. Molina MJ, Mayor AM, Franco AE, Morell CA, Lopez MA, Vila LM. Prevalence of systemic lupus erythematosus and associated comorbidities in Puerto Rico. J Clin Rheumatol 2007;13:202-204.

36. Lerang K, Gilboe I, Garen T, Thelle DS, Gran JT. High in- cidence and prevalence of systemic lupus erythematosus in Norway. Lupus 2012;21:1362-1369.

37. Barnabe C, Joseph L, Belisle P, et al. Prevalence of systemic lupus erythematosus and systemic sclerosis in the First Nations population of Alberta, Canada. Arthritis Care Res (Hoboken) 2012;64:138-143.

38. Grant WB. Solar UV-B radiation is linked to the geographic variation of mortality from systemic lupus erythematosus in the USA. Lupus 2004;13:281-282.

39. Baker SB, Rovira JR, Campion EW, Mills JA. Late onset systemic lupus erythematosus. Am J Med 1979;66:727-732.

40. Uribe AG, McGwin G Jr, Reveille JD, Alarcon GS. What have we learned from a 10-year experience with the LUMINA (Lupus in Minorities; Nature vs. nurture) cohort? Where are we heading? Autoimmun Rev 2004;3:321-329.

41. Samanta A, Feehally J, Roy S, Nichol FE, Sheldon PJ, Walls J. High prevalence of systemic disease and mortality in Asian subjects with systemic lupus erythematosus. Ann Rheum Dis 1991;50:490-492. 